\title{
Evaluation of Plasmodium Infestation and Malarial Complications among Pre-School Going Children in District Lower Dir, Pakistan
}

\author{
Jehan Zeb (Corresponding author) \\ MPhil. Zoology, Department of Zoology, University of Hazara, Pakistan \\ Tel: 92-300-971-8250 E-mail: jehanzeb_zoology@yahoo.com \\ Mian Sayed Khan \\ Asistan Prof. Department: Zoology, Hazara University, Mansehra Pakistan \\ E-mail: miansayedkhan@gmail.com
}

\begin{abstract}
Naseer Ullah
PhD scholar, Department: Animal sciences, Quaid-i-Azam University, Islamabad, Pakistan E-mail: naseeru17@gmail.com
\end{abstract}

\section{Hamid Ullah}

PhD Scholar, Department of Zoology, University of Peshawar, Pakistan

E-mail: attitude.khan@gmail.com

\section{Musharaf Khan}

MPhil Zoology, Department of Zoology, Hazara University, Mansehra Pakistan

E-mail: musharafzoology33@gmail.com

Ghulam Nabi (Corresponding author)

MPhil Endocrinology, Department: Animal sciences, Lab: Reproductive neuro-endocrinology Quaid-i-Azam University, Islamabad, Pakistan.

Tel: 92-345-811-2741Ｅ-mail: ghulamnabiqau@gmail.com 
Abid Ali

Institute of Biotechnology and Genetic Engineering

The University of Agriculture, Peshawar, 25130, Khyber Pakhtunkhwa, Pakistan

Tel: 92-345-918-1648Ｅ-mail: uop_ali@yahoo.com

Received: March 2, 2015 Accepted: March 19, 2015

doi:10.5296/jbls.v6i2.7174ＵRL: http://dx.doi.org/10.5296/jbls.v6i2.7174

\begin{abstract}
The purpose of this study was to show Plasmodium species burden and symptoms consistent with malaria related complications among pre-school going children in North Western part of Pakistan (Timergara, Munda, Maidan, Samar Bagh and Talash). A total of 1312 blood samples were collected during winter, autumn and summer (2011), from males $(808,61.5 \%)$ and females (504, 38.4\%). Microscopy and rapid diagnostic tests (RDT) were used for the detection of plasmodium species. Questionnaires were also designed to collect information about the health conditions of malarial symptomatic children. Overall data revealed that $6.9 \%$ samples were infected, with Plasmodium vivax (96.7\%), Plasmodium falciparum (2.1\%) and mixed species (P. vivax and P. falciparum) (1.0\%). Highest infection rate was recorded in autumn $(2.87 \%)$ followed by summer $(2.45 \%)$ and winter $(1.73 \%)$. Among malaria symptomatic children symptoms like severe temperature $(9.85 \%)$ lower RBS count $(3.7 \%)$, Glucose 6-phosphate dehydrogenase (G-6PD) deficiency $(0.65 \%)$, respiratory distress $(0.65 \%)$, neonatal sepsis $(0.64 \%)$ and low birth weight $(0.42 \%)$ were observed. Shortly malaria control efforts should be taken with an emphasis on improving species diagnosis and treatment availability in district Dir Lower.
\end{abstract}

Keywords: Plasmodium, Malaria, Pakistan, Prevalence, Epidemiology, Microscopy

\title{
1. Introduction
}

Malaria is an overwhelming ailment with high mortality impact in tropical world. It counts for approximately 350 to 500 million clinical infections and 1 to 3 million deaths per annum throughout the world (Schantz-Dunn and Nour, 2009). Pregnant women, children, and immune-compromised individuals have the highest mortality rate mostly in the Sub-Saharan Africa (WHO, 2007). All known species of Plasmodium can affect pregnant women increasing the chances of malarial susceptibilities as compared to non-pregnant women (Rogerson et al., 2007). Through repeated assaults of malaria, children become vulnerable to other diseases like diarrhea and respiratory distress, increasing death rates (Molineaux, 1997). Plasmodium falciparum and Plasmodium vivax are the most prevalent species andresponsible agents for low birth weight (Hartman et al., 2010). Besides low birth weight, other complications can also occur due to $P$. falciparum and $P$. vivax infection which include 
maternal anemia, neonatal sepsis, respiratory distress and fetal growth restriction (Nosten et al., 1999). In addition, malaria can cause metabolic acidosis (English et al., 1997), a clinical complication of respiratory distress both in children and adults (Mwangoka et al., 2008), and an indicator of poor health consequences (Taylor and White, 2002).

Pakistan has tropical climatic condition with an extensive irrigation system where after monsoon rainfall, large ditches are filled with stagnant water suitable for mosquito breeding. Although malaria year-round transmission continues however, it becomes severe after raining (Lathia and Joshi, 2004). Despite of malaria prevalence throughout Pakistan, local data does not properly demonstrate the disease epidemiology (Khan et al., 2004). Northwest zone of Pakistan consists of agricultural bushes where crop cultivation provides better sites for malaria vectors growth, increasing subsequent infection risks. Present study was conducted for the better comprehension of malarial parasites prevalence and malaria related complications in Northwest border between Afghanistan and Pakistan.

\section{Materials and Methods}

\subsection{Study Design}

Present study was conducted in North Western zone of Pakistan. This zone is situated at the border of Afghanistan where refugees are migrating across the border increasing the risk of disease transport. A questionnaire with household interview was developed which include questions such as sex, age, socio-economic status, previous exposure to malaria, home environmental condition and presence or absence of domestic animals to get information about symptomatic patients.

\subsection{Ethical Consideration}

Approved institutional guidelines by local ethical committee were followed during current study and ethical clearances for scientific studies were obtained from the Hazara University, Pakistan. After discussing the objective of the study, written permission were also obtained from the hospitals visited for sample collections.

\subsection{Collection of Blood Samples}

A total of 1312 blood samples of children in age range between 0.0 to 5 years were collected randomly in a $200 \mu \mathrm{l}$ EDTA-coated tubes from overall five urban and rural areas (Timergara, Munda, Talash, Samar Bagh and Maidan). Out of 1312 total samples, 808 (61.5\%) samples were taken from males and 504 (38.4\%) from females visiting health care centers.

\subsection{Preparation of Thick and Thin Smears}

For making blood film, fingertips were washed with $70 \%$ alcohol followed by pricking with a new sterilized lancet. Two new slides were used to make a smear each for blood film and smear preparation. Thick and thin smears were prepared on same slide. After pricking, the second blood drop was collected on the glass slide. Thin smear was fixed using methyl alcohol followed by staining with Giemsa stain as described previously (Russell, 1963). All the slides with immersion oil were observed under stereomicroscope. 


\subsection{Rapid Diagnostic Test (Rdts)}

Blood was taken from collected samples using new sterilized syringe and transferred into an EDTA (ethylenediamine tetra acetic acid) tube containing anti-coagulant tube (SD Bioline). A drop $(\sim 20 \mu \mathrm{l})$ of blood taken from anti-coagulant tube was dispensed into the round sample well of the rapid diagnostic test kit (SD Bioline Malaria kit) and 4 drops of assay diluents (reagent) were added into the assay diluents well according to the manufacturer instructions. The results were observed after 15 minutes. Test was considered positive with the appearance of two lines and negative with the appearance of a single control line. Appearance of all three lines revealed the mixed infection ( $P$. vivax and $P$. falciparum).

\subsection{Red Blood Cells Count}

The collected blood was taken immediately into a $0.5 \mathrm{ml}$ micro tube. The tube was capped and the contents of the tube were gently mixed by flicking with the anticoagulant to avoid clots formation. Hematological assessment of each sample including red blood cell counts, hemoglobin and platelets was performed using Medonic hematology analyzer.

\subsection{Statistical Analysis}

Obtained data was analyzed using Statistix version 9. The independent variables examined include gender, age, and seasons while the outcome was the percentage of malarial parasite incidence and its infections. Chi-square test was used to check significance association and $P$ value $<0.05$ was considered statistically significant.

\section{Results}

The overall findings of the current work show that 91/1312 (6.9\%) cases were positive for malarial parasites with species specific burden of $96.7 \%$ (P. vivax), $2.1 \%$ (P. falciparum), and $1.0 \%$ mixed infection ( $P$. vivax and $P$. falciparum). Out of 1312 examined samples, $P$. vivax was found with highest rate $(88,6.7 \%)$ followed by $P$. falciparum $(2,0.2 \%)$ and mixed infection $(1$, $0.1 \%$ ) (Table 1).

Table 1. Plasmodium burden among different age groups of male and female pre-school going children

\begin{tabular}{|c|c|c|}
\hline \multicolumn{2}{|c|}{ Male } & Female \\
\hline Age group & Affected population\% & Affected population\% $\left(P^{*}\right.$ values $)$ \\
\hline $0.0-1$ & 2.13 & 2.25 \\
$1.1-2$ & 2.46 & 2.73 \\
$2.1-3$ & 1.6 & $1.44>0.05$ \\
\hline $3.1-4$ & 2.38 & 2.71 \\
\hline $4.1-5$ & 2.5 & 2.74 \\
Species & & \\
$P$. vivax & 6.33 & 7.11 \\
P. falciparum & 0.23 & 0.00 \\
Mixed & 0.11 & 0.00 \\
\hline
\end{tabular}


$\mathrm{P}^{*}$ value was calculated using Chi-Square test

Pre-school going male children within age range between 4.1 to 5 years were found highly affected $(2.5 \%)$ followed by 1.1 to 2 years children $(2.4 \%)$, whereas lowest number of affected pre-school going children was recorded in the age range between 2.1 to 3 years $(1.62 \%)$. In case of malarial parasite prevalence, data revealed that highest percentage of pre-school going children was affected with $P$. vivax $(6.33 \%)$ followed by $P$. falciparum $(0.23 \%)$ and mixed infection $(0.12 \%)$ (Table 1$)$.

Pre-school going female children were also examined for the prevalence of malarial parasites. Highest percentage $(2.73 \%)$ of affected pre-school going female children was in the age range between 4.1 to 5 years, while lowest percentage $(1.44 \%)$ was observed in the age range between 2.1 to 3 years. Among pre-school going female children, highest percentage $(7.11 \%)$ was affected with $P$. vivax while $P$. falciparum and mixed infection was not observed (Table 1). No significant association was observed between both age and gender with malaria infection.

Among the positive samples high percentage of pre-school going male and female children positive for malaria, showed symptoms like severe temperature $(49.45 \%)$, lower RBS count (3.7\%), Glucose 6-phosphate dehydrogenase (G-6PD) deficiency $(0.65 \%)$, respiratory distress $(0.65 \%)$, neonatal sepsis $(0.64 \%)$ and low birth weight $(0.42 \%)$ were observed (Table 2$)$.

Table 2. Clinical complications and symptoms consistent with malaria infection among pre-school going children

\begin{tabular}{|l|c|}
\hline Clinical manifestations & Affected population\% \\
\hline Temperature & 49.45 \\
\hline Lower RBC count & 3.7 \\
\hline G-6PD deficiency & 0.65 \\
\hline Respiratory distress & $0.65 \%)$ \\
\hline Neonatal sepsis \\
Low birth weight
\end{tabular}

Highest prevalence of malarial parasites among affected pre-school going children was found in autumn $(2.87 \%)$ followed by summer $(2.45 \%)$ and lowest percentage was recorded in winter (Table 3). Statistically significant association was observed between malaria infection and different seasons. P value was calculated using Chi-Square test.

Out of 717 collected samples in urban area, $40(5.57 \%)$ cases were screened positive for malarial parasites. Differently, out of 595 samples from rural areas, 51 (8.57\%) were screened positive. The positive cases for $P$. vivax using microscopy and RDTs were 88 (6.90\%) and 86 $(6.50 \%)$ respectively. In case of $P$. falciparum using microscopy and RDTs, positive cases were $2(0.20 \%)$ and $1(0.10 \%)$, respectively. Mixed infections were detected equally using both methods $1(0.10 \%)$. 
Table 3. Seasonal burden of Plasmodium species in affected population

\begin{tabular}{|c|c|}
\hline Season & Affected population $\% P$ values \\
\hline Autumn & 2.87 \\
\hline Summer & $2.45<0.05$ \\
\hline Spring & 2.07 \\
\hline Winter & 1.73 \\
\hline
\end{tabular}

$\mathrm{P}$ value was calculated using Chi-Square test

\section{Discussion}

Information on malaria burden and transmission route during infancy especially in the neonatal period is scarce, inconclusive and contradictory (Khan et al., 2006). Although malaria as a major public health problem in Pakistan is largely attributed to $P$. vivax however, $P$. falciparum and mixed species infections are also prevalent (Khattak et al., 2013). Since handful of malaria epidemiological studies have been conducted in parts of Pakistan, however, the assessment of malaria burden in pre-school going children have been hindered. Therefore, the aim of current survey was to provide an updated report on Plasmodium burden and malaria related complications in pre-school going children in north western Pakistan.

As compared to previous reports of malariometric surveys in endemic regions of Pakistan (Olanrewaju, 1999), malarial parasites prevalence $(6.9 \%, 91 / 1312)$ was found moderately higher during the current survey. Variations in malaria prevalence at different regions of current study areas may be due to the differences in local geographic and climatic conditions (Singh et al., 2009). More possibly, this zone is rushed by Afghanistan refugees and their migration across the border may help the disease transport resulting infection variations (Suleman, 1988). Similar conditions have been reported when malaria was wiped out from Uzbekistan; however the disease reappeared due to the public cross border movement with Tajikistan (Severini et al., 2004).

The rural areas are prone to malaria where the life standard parameters are ignored due to poverty and lack of awareness (Hozhbari et al., 2000). Similarly, high prevalence of malarial parasites was observed in rural areas (8.5\%) as compared to urban areas $(5.5 \%)$ during current study. Irrigation practices in the current study sites produce water logs suitable for malaria vector breeding (Afrane et al., 2004), increasing the possibilities of high malarial parasites prevalence. Other possibility for this high prevalence also include the lack of health facilities, rice cultivation, poor sanitation and scattered houses allowing breeding points for malaria vectors in rural areas (Awan and Jan, 2008).

Moderate temperature is a responsible factor influencing Plasmodium flourishment and high rate of malaria infections. Indeed, high temperature during rainy season is a responsible factor for high spread of malarial infection (Hay et al., 2003). Therefore, current malarial parasites high prevalence in autumn maybe attributed to local stagnant water ponds that enhance vector 
breeding after post monsoon period (Nizamani and Memon, 1995). The time needed for the completion of Plasmodium in malarial vectors is inversely proportional to the temperature. Lower temperature for the $P$. vivax is $15^{\circ} \mathrm{C}$ (Macdonald, 1957) and at a temperature below $19^{\circ} \mathrm{C}$, sporogony of the $P$. falciparum fails to complete life cycle. The current lowest infection rate in winter is possibly due dry season and fall in temperature (Beadle et al., 1995). Accordingly, temperature as a major clinical manifestation for malaria during present study is in agreement with the WHO report (WHO).

Malaria can result in low birth weight (LBW), which is an important risk factor responsible for infant mortality (Guyatt and Snow, 2004). Our results were parallel with previous reports showing significant lower birth weights of malaria infected children (Anagnos et al., 2001). Also, comparatively lower level of hemoglobin and RBCs count was observed in children (3.7\%) infected malarial parasite as compared to non-infected. Studies have been carried out in Africa where approximately $75 \%$ of children less than 5 year of age are facing anemia (DeMaeye and Adiels-Tegman, 1985). G-6PD is a genetic red blood cells disorder found in $P$. falciparum endemic regions including Africa, Asia, Mediterranean region and Middle East. Demonstrations show that G-6PD deficient people have strong resistance to $P$. vivax infection (Leslie et al., 2010). Diagnosis and management of G-6PD deficiency is a crucial aspect in malaria control and elimination (Lorenz et al., 2013). G-6PD deficiency was also observed an important feature of malaria prevalence during current work.

Positive cases for $P$. vivax were $88(6.7 \%)$ and 86 (6.5\%) using microscopy and RDTs analysis, respectively. In case of $P$. falciparum, $2(0.21 \%)$ and $1(0.1 \%)$ cases were observed positive using microscopy and RDTs, respectively. This small difference between the two methods may be due to the use and effects of anti-malarial drugs (Carol et al., 1998). Previously, P. vivax trophozoites seen under microscopic were unidentified by rapid device due to anti-malarial drugs that kill the parasites which remain unable to secrete Plasmodium lactate dehydrogenase (PLDH) (Carol et al., 1998). Our findings are parallel with previous reports suggesting microscopy reliability as compared to rapid device for malaria parasite detection (Carol et al., 1998).

\section{Conclusion}

In summary, $P$. vivax, $P$. falciparum and mixed infections were observed in pre-school going children using microscopy and RDTs. The prevalence of $P$. vivax was higher as compared to $P$. falciparum infecting both genders in rural and urban areas. We strongly recommend malarial symptomatic pre-school going children with in current study areas should be properly treated with antimalarial drugs to avoid life loss.

\section{Acknowledgements}

The authors gratefully acknowledge the technical support by staff of Government Head Quarter Hospital Timergara and Medical Laboratories. The authors also acknowledged Higher Education commission, Pakistan for financial support.

\section{References}


Afrane YA, Klinkenberg E, Drechsel P, Owusu-Daaku K, Garms R, Kruppa T. (2004). Does irrigated urban agriculture influence the transmission of malaria in the city of Kumasi, Ghana? Acta Tropica, 89, 125-34. http://dx.doi.org/10.1016/j.actatropica.2003.06.001

Anagnos D, Lanoie LO, Palmieri JR, Ziefer A, Connor DH (2001). Effects of placental malaria on mothers and neonates from Zaire. J Parasitol Res, 72(1), 57-64.

Awan ZR, Jan AH (2008). Rice fields in relation to malaria in district Bannu, NWFP. Proc Pakistan Congress Zoology, 28, 11-21.

Beadle C, McElroy PD, Oster CN, Beier JC, Oloo AJ, Onyango FK, Chumo DK, Bales JD, Sherwood JA, Hoffman SL (1995). Impact of transmission intensity and age on Plasmodium falciparum density and associated fever: implications for malaria vaccine trial design. Int. J. Infect, 172, 1047-1054. http://dx.doi.org/10.1093/infdis/172.4.1047

Carol J, John F, Lindo W (1998). Evaluation of the optimal test for diagnosis of Plasmodium falciparum and Plasmodium vivax malaria. Clinical Microbiology, 36(1), 203-206.

DeMaeyer E, Adiels-Tegman M (1985). The prevalence of anemia in the world. World Health Statistics Quarterly,38, 302-316.

English M, Sauerwein R, Waruiru C, Mosobo M, Obiero J, Lowe B, Marsh K (1997). Acidosis in severe childhood malaria. QJM, 90, 263-70. http://dx.doi.org/10.1093/qjmed/90.4.263

Guyatt HL, Snow RW (2004). Impact of Malaria during Pregnancy on Low Birth Weight in Sub-Saharan Africa. Clin. Microbiol. Rev, 17(4), 760-769. http://dx.doi.org/10.1128/CMR.17.4.760-769.2004

Hartman TK, Rogerson SJ, Fischer PR (2010). The impact of maternal malaria on newborns. Ann Trop Paediatr, 30(4), 271-82. http://dx.doi.org/10.1179/146532810X12858955921032

Hay SI, Noor AM, Nelson A, Tatem AJ (2003). in press. The influence of large-scale population maps on the accuracy of burden of disease estimates. American Journal of Epidemiology.

Hozhbari S, Akhtar S, Rahbar MH, Luby SP (2000). Prevalence of Plasmodium positivity among the children treated for malaria, Jhangara Sindh. J Pak Med Assoc, 5, 401-5.

Khan HU, Khattak AM, Khan MH, Mahsud IU, Shah SH (2006). A study of prevalence of malaria in adult population of D. I. Khan, Pakistan. Biomedia, 2, 99-104.

Khan MA, Smego RA, Razi ST, Beg MA (2004). Emerging drug - resistance and guidelines for treatment of malaria. J Col Phys Surg Pak, 14, 319- 324.

Khattak AA, Venkatesan M, Nadeem MF, Satti HS, Yaqoob A, Strauss K, Khatoon L, Malik SA, Plowe CV (2013). Prevalence and distribution of human Plasmodium infection in Pakistan. Malar J, 12, 297. http://dx.doi.org/10.1186/1475-2875-12-297

Lathia TB, Joshi R (2004). Can hematological parameters discriminate malaria from non-malarious acute febrile illness in the tropics? Indian J Med Sci, 58(6), 239-244. 


\section{$\triangle$ Macrothink}

Leslie T, Briceno M, Mayan I, Mohammed N, Klinkenberg E, Sibley CH, Whitty CJM, Rowland M (2010). The impact of phenotypic and genotypic G6PD deficiency on risk of Plasmodium vivax infection: a case-control study amongst Afghan refugees in Pakistan. Plos Med, 7: e1000283. http://dx.doi.org/10.1371/journal.pmed.1000283

Lorenz VS, Auburn S, Espino F, Shanks D, Cheng Q, McCarthy J, Baird5 K, Moyes C, Howes R, Ménard D, Bancone G, Winasti-Satyahraha A, Vestergaard LS, Green J, Domingo G, Yeung S, Price R. (2013). Review of key knowledge gaps in glucose-6-phosphate dehydrogenase deficiency detection with regard to the safe clinical deployment of 8-aminoquinoline treatment regimens: a workshop report. Malaria Journal, $12,112$. http://dx.doi.org/10.1186/1475-2875-12-112

Macdonald G (1957). The epidemiology and control of malaria. London: Oxford University Press.

Molineaux L (1997). Malaria and mortality: some epidemiological considerations. Ann Trop Med Parasitol, 91(7), 811-825. http://dx.doi.org/10.1080/00034989760572

Mwangoka GW, Kimera SI, Mboera LE (2008). Congenital Plasmodium falciparum infection in neonates in Muheza District Tanzania. Malar, J 7, 117. http://dx.doi.org/10.1186/1475-2875-7-117

Nizamani MA, Memon MH (1995). Cerebral malaria in children: a study of 50 cases. Pakistan Pediatrics Journal, 19, 1-7.

Nosten F, McGready R, Simpson JA, Thwai KL, Balkan S, Cho Thei, Hkirijaroen L, Looareesuwan S, White NJ (1999). Effects of Plasmodium vivax malaria in pregnancy. Lancet, 354, 546-549. http://dx.doi.org/10.1016/S0140-6736(98)09247-2

Olanrewaju WI (1999). Malaria in the neonate: report of 2 cases. West Afr J Med, 18(2), 139-40.

Rogerson SJ, Hvjjd L, Duffy PE, Leke RFG, Taylor D (2007). Malaria in pregnancy: $\begin{array}{llll}\text { pathogenesis and immunity. } & \text { Lancet, } & \text { 105-116. }\end{array}$ http://dx.doi.org/10.1016/S1473-3099(07)70022-1

Russell ES (1963). Techniques for the study of anemia in mice. In W.J.Burdette [ed.] Methodology in Mammalian Genetics. Holden-Day, San Francisco. 558-564.

Schantz-Dunn J, Nour NM (2009). Malaria and Pregnancy: A Global Health Perspective. Rev Obstet Gynecol, 2(3), 186-192.

Severini C, Menegon M, Di Luca MD, Abdullaev I, Majori G, Shavkat A, Razakov Gradoni L (2004). Risk of Plasmodium vivax malaria reintroduction in Uzbekistan: genetic characterization of parasites and status of potential malaria vectors in the urkhandarya region. R Soc Trop Med Hyg, 98, 585-592. http://dx.doi.org/10.1016/j.trstmh.2004.01.003

Singh V, Mishra N, Awasthi G, Dash AP, Das A (2009). Why is it important to study malaria $\begin{array}{lllll}\text { epidemiology in India? Trends } & \text { Parasitol, } & \text { 25, }\end{array}$ 
http://dx.doi.org/10.1016/j.pt.2009.06.004

Suleman M. Prevalence of malaria in afghan refugees in Pakistan (1988). R Soc Trop Med Hyg, 88(1), 44-47. http://dx.doi.org/10.1016/0035-9203(88)90257-X

Taylor WRJ, White NJ (2002). Malaria and the lung. Clin Chest Med, 23, 457-468. http://dx.doi.org/10.1016/S0272-5231(02)00004-7

WHO: Malaria in infants. World Health Organization, 2007.

World Health Organization; Implementation of the Global malaria control strategy: report of a WHO study group on the implementation of the global plan of action for malaria control, 1993-2000 Geneva. (WHO Technical Report Series, No 839).

\section{Copyright Disclaimer}

Copyright for this article is retained by the author(s), with first publication rights granted to the journal.

This is an open-access article distributed under the terms and conditions of the Creative Commons Attribution license (http://creativecommons.org/licenses/by/3.0/). 